\title{
Erratum to: The impacts of coordinative exercise on executive function in kindergarten children: an ERP study
}

\author{
Yu-Kai Chang $\cdot$ Yu-Jung Tsai $\cdot$ Tai-Ting Chen • \\ Tsung-Min Hung
}

Published online: 6 June 2013

(C) Springer-Verlag Berlin Heidelberg 2013

Erratum to: Exp Brain Res (2013) 225:187-196

DOI 10.1007/s00221-012-3360-9

Unfortunately, in the original publication of this article, the y-axis and SEM were inadvertently mislabeled, in Fig. 2. It should be presented as follows. These mistakes do not affect any conclusions of the research.

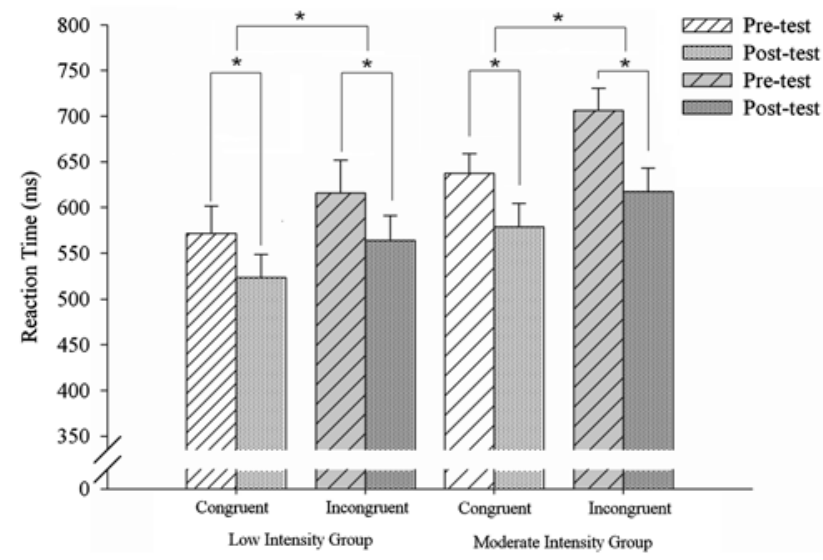

Fig. 2 Reaction time to flanker trials and times between two exercise intensity groups. Data are mean \pm SEM. $* p<.05$

The online version of the original article can be found under doi:10.1007/s00221-012-3360-9.

Y.-K. Chang

Graduate Institute of Athletics and Coaching Science,

National Taiwan Sport University, Taoyuan, Taiwan

e-mail: yukaichangnew@gmail.com

Y.-J. Tsai · T.-T. Chen · T.-M. Hung ( $\varangle)$

Department of Physical Education, National Taiwan Normal

University, No. 162, Sec. 1, Heping E. Rd., Da' an Dist.,

Taipei 10610, Taiwan

e-mail: ernesthungkimo@yahoo.com.tw 